\title{
Development of Simple Green Spectrophotometric and Conductometric Methods for Determination of Cephalosporins in Pure, Pharmaceutical Dosage forms and Human Urine.
}

\author{
Rania A. Sayed *a, Wafaa S. Hassan ${ }^{a}$, Magda Y. El-Mammli ${ }^{a}$ \& Abdalla. Shalaby ${ }^{a}$ \\ ${ }^{a}$ Department of Analytical Chemistry, Faculty of Pharmacy, Zagazig University, 44519, Zagazig , Egypt.
}

raniaadelsayed@yahoo.com

\begin{abstract}
Five Simple, accurate and rapid spectrophotometric and conductometric methods were developed for the determination of four third generation cephalosporins, namely, cefotaxime sodium (I), cefoperazone sodium (II), ceftazidime pentahydrate (III) and cefdinir (IV) in pure active ingredient, pharmaceutical dosage forms and human urine. Method $A$ : is based on the reaction of the sulphide ions produced from the alkaline hydrolysis of the cited four drugs with $\mathrm{P}$ - aminophenol (PAP). This reaction results in a thionine dye (phenothiazine derivative) formation which exhibits maximum absorbance at $545 \mathrm{~nm}$. Method B: is based on oxidation of drug (I and III) with a known excess of $n$-bromosuccinimide (NBS) in acidic medium followed by the determination of unreacted amount of $n$-bromosuccinimide with metol and sulphanilic acid. The purple-red reaction product exhibits maximum absorbance at $520 \mathrm{~nm}$. Method $C$ : is based on the formation of yellow chelate between drug (IV) and palladium (II) chloride in buffered medium ( $\mathrm{pH} 3.5$ ) with an absorption maximum at $314 \mathrm{~nm}$. Method D: is based on the reaction of drug (IV) with aqueous ninhydrin to give yellow colored product in the presence of bicarbonate with an absorption maximum at $433 \mathrm{~nm}$. Method E: A conductometric method is based on the reaction of the four cited drugs with phosphotungstic acid (PTA) forming an ion associate in aqueous medium. Validation of the proposed methods was carried out. All proposed methods were successfully applied for the commercial dosage forms of the cited drugs. Method $\mathrm{C}$ was successfully applied for the determination of cefdinir in human urine.
\end{abstract}

\section{Keywords}

Cephalosporins; green; spectrophotometric; conductometric; pharmaceutical preparations and human urine.

\section{Council for Innovative Research}

Peer Review Research Publishing System

Journal: Journal of Advances in Chemistry

Vol. 4, No. 3

editor@cirworld.com

www.cirworld.com, member.cirworld.com

532 | P a g e

October 18,2013 


\section{INTRODUCTION}

Cephalosporins are one of the most important type of antibiotics used vary widely. Analysis of these antibiotics is challenge due to their sensitivity and instability to different conditions. Cephalosporins are related to the penicillins in their structures and pharmacology. Like the penicillins, cephalosporins have a $\beta$-lactam ring in their structures that interferes with bacterial cell wall synthesis. They are used for the treatment of infections caused by Gram (+) and Gram (-) bacteria. They are among the safest and the most effective broad-spectrum bactericidal antibiotics and therefore, they are the most frequently prescribed class of antibiotics [1]. Cephalosporins are divided into first-, second-, third-, and fourth-generation agents. The studied drugs are four of third- generation agents.

Several methods have been reported for cephalosporins determination. The official procedures for the cited drugs (I ,II ,III and IV) utilize liquid chromatography $[2,3]$ which is expensive .The literature reveals that many methods were developed for cephalosporins determinations $[4,5,6]$.

The majority of the reported methods were HPLC methods which require expensive equipment, chemicals and intensive sample preparation. Use of organic solvents and hazardous materials is the common feature in most previous methods. So the aim of this work is to develop five simple, accurate, precise, and rapid green spectrophotometric and conductometric methods for the estimation of the cited drugs in pure, pharmaceutical dosage forms and human urine. The proposed methods have higher sensitivity than other methods. With these methods, chemist can carry out cefotaxime sodium, cefoperazone sodium, ceftazidime pentahydrate and cefdinir analysis at low cost without interference from excipients or biofluid matrix.

\section{EXPERIMENTAL}

\subsection{Instruments}

Shimadzu recording spectrophotometer UV 1201 equipped with $10 \mathrm{~mm}$ matched quartz cells and conductometer model 470 portable conductivity / TDS meter, 25 DEG.C-C10 dip-type cell with a cell constant, $\mathrm{K}_{\text {cell }}$ of 1.09 were used. Digital analyzer $\mathrm{pH}$ meter (USA) was employed for $\mathrm{pH}$ measurment.

\subsection{Reagents and materials}

All chemicals and materials were of high analytical grade, and double distilled water was used through the work.

1- Cefotaxime sodium, cefotax vials labelled to contain $1000 \mathrm{mg}$ cefotaxime sodium per vial (EGYPTIAN INT. PHARMACEUTICAL INDUSTRIES CO. E.P.I.C.O. Egypt)

2- $\quad$ Cefoperzone sodium, cefozon vials labelled to contain $1000 \mathrm{mg}$ cefoperzone sodium per vial ( EGYPTIAN INT. PHARMACEUTICAL INDUSTRIES CO. E.P.I.C.O. Egypt)

3- Ceftazidime pentahydrate, cefidime vials labelled to contain (ceftazidime pentahydrate - sodium carbonate mixture equivalent to $500 \mathrm{mg}$ ceftazidime per vial).

4- Cefdinir (Bristol - Myers Squibb Pharmaceutical Co., Cairo, Egypt). Dinar capsules labelled to contain $300 \mathrm{mg}$ cefdinir per capsule, Dinar suspension labelled to contain $125 \mathrm{mg}$ cefdinir per $5 \mathrm{~mL}$ (Kahira Pharma Co for ADWIA Co. S.A.E 10th of Ramadan City, Egypt)

5- P-Aminophenol (Acros Belgium), was prepared as $10^{-2} \mathrm{M}$ as by dissolving $0.27 \mathrm{~g}$ PAP in $200 \mathrm{~mL}$ distilled water, $5 \mathrm{~mL}$ concentrated sulphuric acid were added and the volume was completed to $250 \mathrm{~mL}$ with distilled water.

6- Zinc acetate ( $0.5 \mathrm{M}$ in $0.1 \mathrm{M}$ sulphuric acid), potassium chloride (2 M aqueous solution), were obtained from Adwic Chemical Company, (Egypt).

7- Ammonium iron(III) sulphate ( SD Fine - Chem Limited (SDFCL), India), $0.5 \mathrm{M}$ solution was prepared in $0.5 \mathrm{M}$ sulphuric acid.

8- N-bromosuccinimide (Sigma Aldrich,Germany) $(0.1 \mathrm{~g} \%$, w/v) aqueous solution.

9- Metol (Sigma Aldrich ,Germany) $(0.2 \mathrm{~g} \%, \mathrm{w} / \mathrm{v})$ aqueous solution.

10- Sulphanilic acid (Sigma Aldrich,Germany) $(0.2 \mathrm{~g} \%, \mathrm{w} / \mathrm{v})$ aqueous solution.

11- Palladium(II) chloride (Sigma, Milwukee, WI,USA) was prepared as $2 \times 10^{-3} \mathrm{M}$ by dissolving $35.5 \mathrm{mg}$ of palladium(II) chloride in $1 \mathrm{~mL}$ of concentrated hydrochloric acid and diluting to $50 \mathrm{~mL}$ with distilled water, with the aid of heat and then the solution was cooled and diluted to $100 \mathrm{~mL}$ with distilled water.

12- Ninhydrin (Sigma, Milwukee, WI,USA) was prepared as $0.5 \%$ aqueous solution.

13- Phosphotungstic acid (Winlab, UK) was prepared as $10^{-2} \mathrm{M}$ aqueous solution.

14- Sulphuric acid, hydrochloric acid and sodium hydroxide were obtained from El-Nasr Chemical Company, (Egypt).

15- Walpole's acetate buffer was prepared by adding different volumes of $0.2 \mathrm{M}$ acetic acid to different volumes of 0.2 M sodium acetate (El-Nasr Chemical Company, Egypt).

16- Sodium Bicarbonate (Saturated Solution) (El-Nasr Chemical Company, Egypt) was prepared by dissolving $25 \mathrm{~g}$ $\mathrm{NaHCO}_{3}$ in $100 \mathrm{~mL}$ of water. Stirring for twenty minutes with a magnetic stirrer was carried out then the clear supernatant was taken by filteration. 


\subsection{Preparation of standard solutions}

1 - For the method A, stock working solutions of drugs $(I, I I, I I)$ were prepared to contain $6 \mathrm{mg} / \mathrm{mL}$, dissolved in double distilled water.For drug (IV), solution of $3 \mathrm{mg} / \mathrm{mL}$ dissolved in $1 \mathrm{~mL} 1 \mathrm{M} \mathrm{NaOH}$ and the volume was completed with double distilled water to the mark

2 - For the method B , Stock working solutions of $0.2 \mathrm{mg} / \mathrm{mL}$ dissolved in $0.2 \mathrm{M}$ and $0.05 \mathrm{M} \mathrm{HCl}$ for drug (I and III) respectively.

3 - For the methods $\mathrm{C}$ and $\mathrm{D}$, solution of $0.2 \mathrm{mg} / \mathrm{mL}$ dissolved in $1 \mathrm{~mL} 1 \mathrm{M} \mathrm{NaOH}$ and the volume was completed with double distilled water to the mark.

4- For the method $\mathrm{E}$, stock working solutions of all drugs were prepared to contain $3 \mathrm{mg} / \mathrm{mL}$.

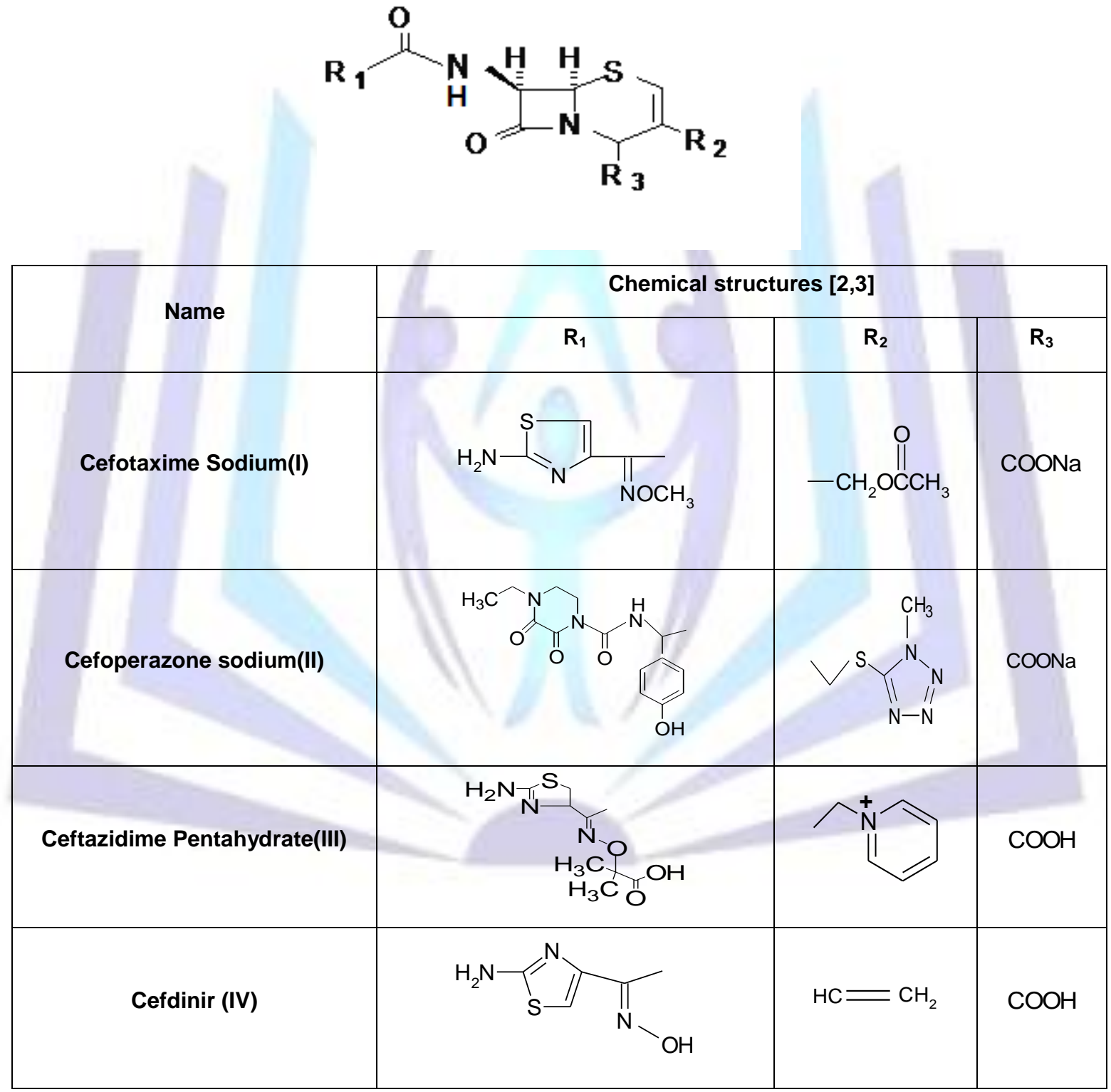

Scheme (1): Chemical structures of the investigated cephalosporin antibiotics. 


\subsection{CALIBRATION PROCEDURES}

\subsubsection{Method A}

Into four sets of $10 \mathrm{~mL}$ volumetric flasks, accurate volumes of the standard solution of each drug containing (0.6-7.2), (1.813.8), (1.2-10.8) and $(0.3-3.6) \mathrm{mg}$ of drug (I, II, III and IV) respectively were transferred and the solutions were completed with $1 \mathrm{M} \mathrm{NaOH}$ to the mark. The flasks were heated in a boiling water bath for 50 minute for drug (I and II) and 60 minute for drug (III and IV) and then cooled to room temperature. One $\mathrm{mL}$ of each of these solutions was transferred into another three sets of $10 \mathrm{~mL}$ volumetric flasks. Two milliliters of zinc acetate solution then the specified volume of $p$ aminophenol and Ammonium iron (III) sulphate solutions were added to each flask. The flasks were shaken for 30 seconds and allowed to stand for the specified time. The volumes were completed to $10 \mathrm{~mL}$ with distilled water Absorbance was measured at $545 \mathrm{~nm}$ against blank solution (Figure 1).

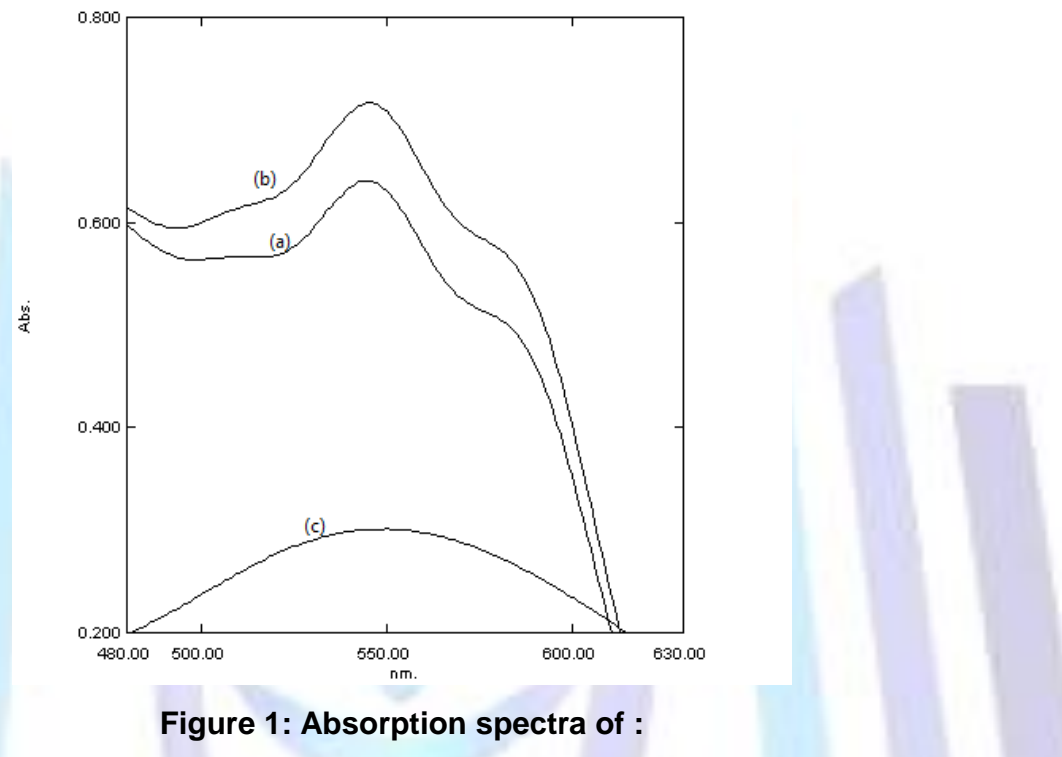

(a) The thionine dye formed through the reaction with $48 \mu \mathrm{g} / \mathrm{mL}$ cefotaxime sodium.

(b) The thionine dye formed through the reaction with $108 \mu \mathrm{g} / \mathrm{mL}$ cefoperazone sodium.

(c) Blank solution.

\subsubsection{Method B}

Into two sets of $10 \mathrm{~mL}$ volumetric flasks, accurate volumes of the standard solution of each drug containing (0.02-0.32) and (0.04-0.32) $\mathrm{mg}$ of drug (I and III) respectively were transferred. To each flask 0.8 and $2 \mathrm{~mL}$ of NBS were added for drug (I and III) respectively. The content was mixed well. The flasks were kept for 15 and 10 min for drug (I and III) respectively with intermittent shaking. Then, the specified volume of metol was added. After 1 minute, the specified volume of sulphanilic acid was added to each flask, The flasks were kept aside for 3 minutes. Then, the volume was diluted to the mark with bidistilled water and mixed well. The absorbances were measured at $520 \mathrm{~nm}$ (Figure 2). Calibration curves were prepared by plotting decreasing values of absorbance against drug concentrations. 


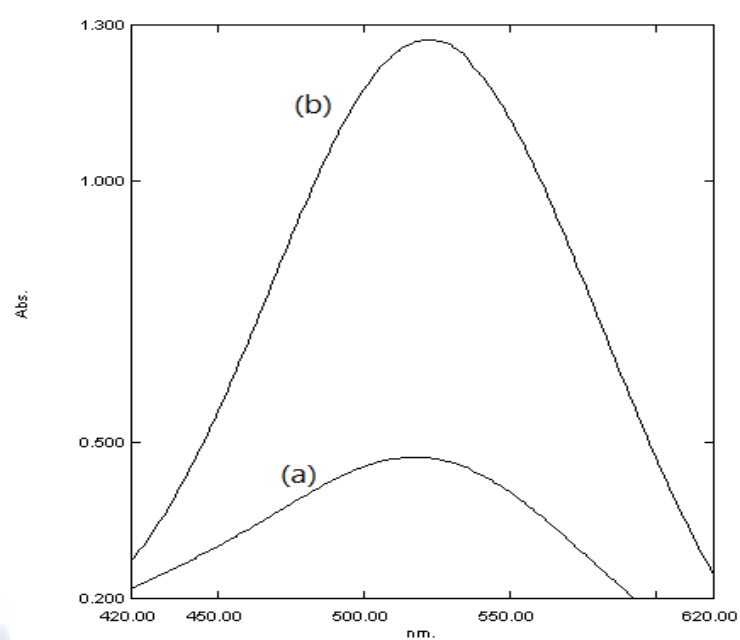

Figure 2: Absorption spectra of:

(a) The reaction between NBS solution and of $17 \mu \mathrm{g} / \mathrm{mL}$ cefotaxime sodium.

(b) Blank solution.

\subsubsection{Method C}

To a set of $10 \mathrm{~mL}$ volumetric flasks, accurately measured aliquots of standard drug (IV) solution in the range of $(0.03$ $0.26) \mathrm{mg}$ were transferred. $2 \mathrm{~mL}$ buffer solution of $\mathrm{pH} 3.5$ were then added, then $0.5 \mathrm{~mL}$ of $2 \mathrm{M}$ potassium chloride and 1 $\mathrm{mL} \mathrm{Pd}(\mathrm{II})$ chloride solution. The solutions were allowed to stand at room temperature $\left(25{ }^{\circ} \mathrm{C}\right)$ for 10 minutes, then diluted to volume with bidistilled water, absorbance was measured at $314 \mathrm{~nm}$ against blank solution (Figure 3).

\subsubsection{Method D}

To a set of $10 \mathrm{~mL}$ volumetric flasks, accurately measured aliquots of standard drug (IV) solution in the range of $(0.04-0.3)$ $\mathrm{mg}$ were transferred and completed to $5 \mathrm{~mL}$ with bidistilled water. $1 \mathrm{~mL}$ of ninhydrin solution followed by $1 \mathrm{~mL}$ of saturated solution of sodium bicarbonate were added to each flask. The flasks were heated in a boiling water bath for 15 minutes, cooled and then diluted to volume with bidistilled water. Absorbance was measured at $433 \mathrm{~nm}$ versus blank solution (Figure 3).

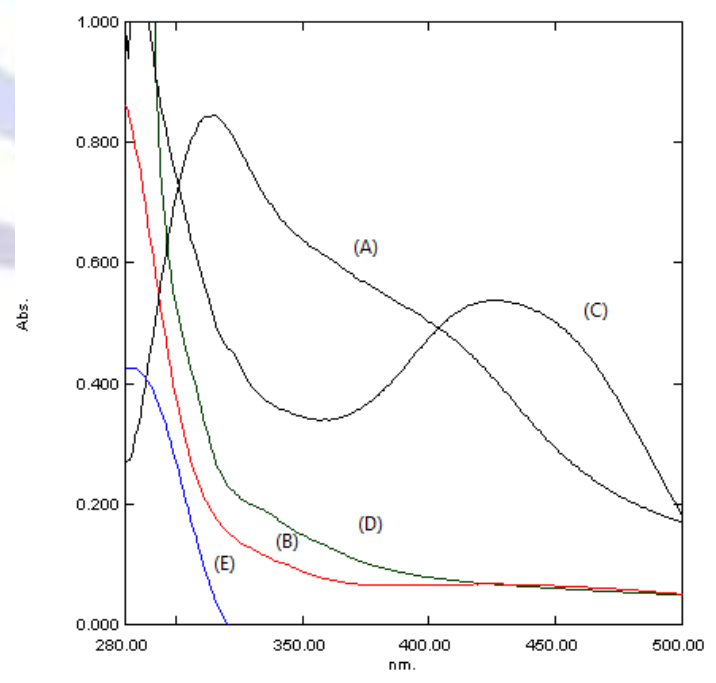

Figure 3: Absorption spectra for:

(A) The complex formed through reaction of of $24 \mu \mathrm{g} / \mathrm{mL}$ cefdinir with $\mathrm{Pd}$ (II) chloride against reagent blank.

(B) $2 \mathrm{~mL}$ buffer solution of $\mathrm{pH} 3.5,0.5 \mathrm{~mL}$ of $2 \mathrm{M} \mathrm{KCl}$ and $1 \mathrm{~mL} \mathrm{Pd(II)} \mathrm{chloride} \mathrm{solution} \mathrm{.}$

(C) The reaction product of $17 \mu \mathrm{g} / \mathrm{mL}$ cefdinir with ninhydrin against reagent blank.

(D) $1 \mathrm{~mL}$ of ninhydrin solution and $1 \mathrm{~mL}$ of saturated solution of $\mathrm{NaHCO}_{3}$.

(E) $24 \mu \mathrm{g} / \mathrm{mL}$ cefdinir against water. 


\subsubsection{Method E}

Aliquots of drug solution containing $(3-30 \mathrm{mg})$ were transferred to a $50 \mathrm{~mL}$ calibrated flasks. Volumes were made up to the mark using bidistilled water and transferred to a beaker. Titration with $10^{-2} \mathrm{M}$ phosphotungstic acid was performed. The conductance was measured subsequent to each addition of phosphotungstic acid solution and after stirring for 2 minutes, the conductance was corrected for dilution [7] using the following equation.

$$
\Omega_{\text {correct }}^{-1}=\Omega^{-1} \text { obs }\left[\left(v_{1}+v_{2}\right) / v_{1}\right]
$$

Where $\Omega^{-1}$ obs is the observed electrolytic conductivity, $v_{1}$ is the initial volume and $v_{2}$ is the volume of phosphotungstic acid solution added. A graph of corrected conductivity versus the volume of added phosphotungstic acid solution was constructed and end-point was estimated (Figure 4).

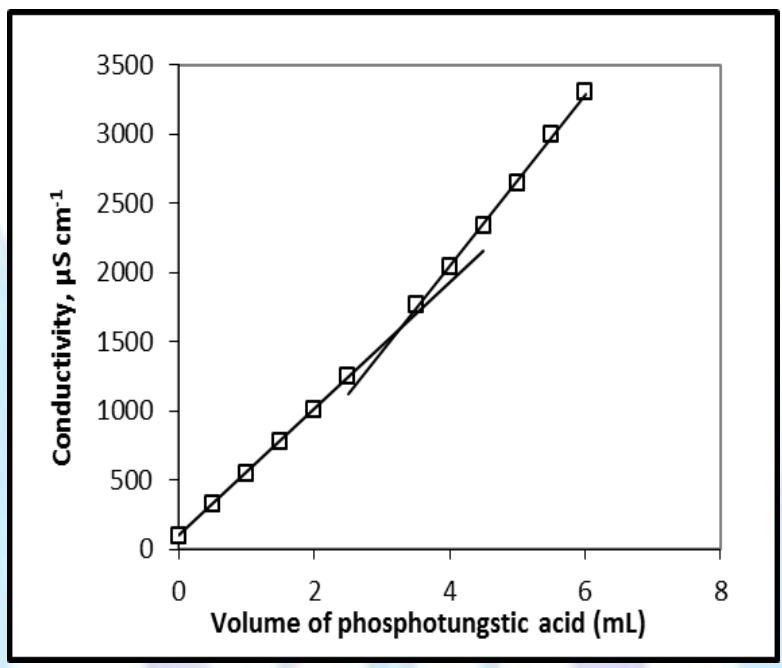

Figure 4: Conductometric titration curve of $15 \mathrm{mg}$ cefoperazone sodium versus $10^{-2} \mathrm{M}$ PTA.

\subsubsection{Preparation and analysis of pharmaceutical preparations}

\subsubsection{For drugs (I, II and III)}

\subsection{Method $A$ and $E$ :}

The conent of one vial was transferred into $100 \mathrm{~mL}$ volumetric flask and the volume was completed with distilled water .Accurate volume of vial equivalent to 300 and $150 \mathrm{mg}$ for method $\mathrm{A}$ and $\mathrm{C}$ respectively was transferred to $50 \mathrm{~mL}$ volumetric flask. The volume was completed with double distilled water and the procedure was completed as under general procedure.

\subsection{For Method B:}

The conent of one vial was transferred into $100 \mathrm{~mL}$ volumetric flask and the volume was completed with $0.2 \mathrm{M}$ and 0.05 $\mathrm{M} \mathrm{HCl}$ for drug (I and III) respectively. Accurate volume of vial equivalent to $10 \mathrm{mg}$ for drug (I and III) was transferred to 50 $\mathrm{mL}$ volumetric flask. The volume was completed with $0.2 \mathrm{M}$ and $0.05 \mathrm{M} \mathrm{HCl}$ for drug (I and III) respectively and the procedure was completed as under general procedure .

\subsubsection{For drug (IV)}

\subsection{For cefdinir capsules:}

The contents of 10 capsules were removed and their weight was determined accurately. The combined contents were mixed and a quantity equivalent to $10 \mathrm{mg}$ for method $C$ and $D$ and equivalent to $150 \mathrm{mg}$ for method $A$ and $E$ was transferred into $50 \mathrm{~mL}$ volumetric flasks, extracted with $1 \mathrm{~mL} 1 \mathrm{M} \mathrm{NaOH}$ and shaken with $10 \mathrm{~mL}$ bidistilled water, then filtered and diluted to $50 \mathrm{~mL}$ with bidistilled water. The assay was completed as under general procedure.

\subsection{For cefdinir suspension:}

An accurately measured volume of the freshly reconstituted oral suspension equivalent to $10 \mathrm{mg}$ for method $\mathrm{C}$ and $\mathrm{D}$ and equivalent to $150 \mathrm{mg}$ for method $\mathrm{A}$ and $\mathrm{E}$ was transferred into $50 \mathrm{~mL}$ volumetric flasks, extracted with $1 \mathrm{~mL} 1 \mathrm{M} \mathrm{NaOH}$ and shaken with $10 \mathrm{~mL}$ distilled water, then filtered and diluted to $50 \mathrm{~mL}$ with distilled water. The assay was completed as under general procedure. 


\subsection{Prepartion and analysis of human urine samples ( for method C)}

Human urine samples were collected freshly from healthy volunteers. Blank urine pool was diluted 1:1 with double distilled water, then spiked with the appropriate amounts of stock solution to prepare samples. The assay was completed as described above.

\section{RESULTS AND DISCUSSION}

Many of the reported methods suffered from poor sensitivity, use of expensive organic solvents and extraction step. The use of organic solvent as the reaction medium is undesirable. Green or environmentally- friendly analytical methods are promising in recent years. Modern analytical methods need to be green without losing accuracy and sensitivity. The aim of the present work was to develop five new sensitive, cost effective methods for the determination of cephalosporins in pure drug, in pharmaceutical preparations and human urine. Method (A) is based on the use of PAP in sulphuric acid and aqueous medium. Method $(B)$ is based on redox reaction in acidic and aqueous medium . Method $(C)$ is based on use of the palladium (II) chloride in walpole acetate buffer $\mathrm{pH} 3.5$, unlike other methods which are based on the use of palladium (II) chloride in DMF [6]. No spectrophotometric method was reported for cefdinir determination in human urine, so method (C) is advantageous in its determining in human urine. Method (D) is based on use of aqueous ninhydrin in bicarbonate medium, unlike other methods which are based on the use of methanolic or ethanolic ninhydrin [8]. Method (E) is based on direct titration of the cited drugs with PTA in aqueous medium. So, all proposed methods are free from usage of hazardous and expensive chemicals. Since inexpensive and easily available chemicals are used, the developed methods are green low cost analytical methods for cefdinir.

\subsection{Method development (Method A)}

Para amino phenol (PAP) was widely used in many analytical methods for pharmaceutical compounds determination. It was used for determination of cimetidine, famotidine, nizatidine, ranitidine hydrochloride [9] and cephalexin [10].

Method A is based on the alkaline hydrolysis of the cited drugs producing the sulphide ions which react with PAP and ferric ions by ring closure redox reaction giving red thionine dye (phenothiazine derivative) .<smiles>Cc1ccc(O)cc1SC1=CC(=O)C=CC1=N</smiles>

Scheme (2): Ring closure redox reaction of PAP with the alkaline hydrolysis product of the cited drugs.

\subsubsection{Optimization of the reaction conditions}

The effect of hydrolysis time, effect of PAP volume, ammonium iron (III) sulphate volume and effect of reaction time were studied. It was found that 50 minutes hydrolysis time for (I and II) and 60 minutes for (III and IV), $4.5 \mathrm{~mL}$ of PAP for (I and II) , $3 \mathrm{~mL}$ for (III) and $4 \mathrm{~mL}$ for (IV) (Figure 5), $1.5 \mathrm{~mL}$ of ammonium iron (III) sulphate for (I,II and III) and $2 \mathrm{~mL}$ for (IV) and 1 minute for (I and II) and 3 minutes for (III and IV) were sufficient to give maximum absorbance. The color produced was stable for 1 hour.

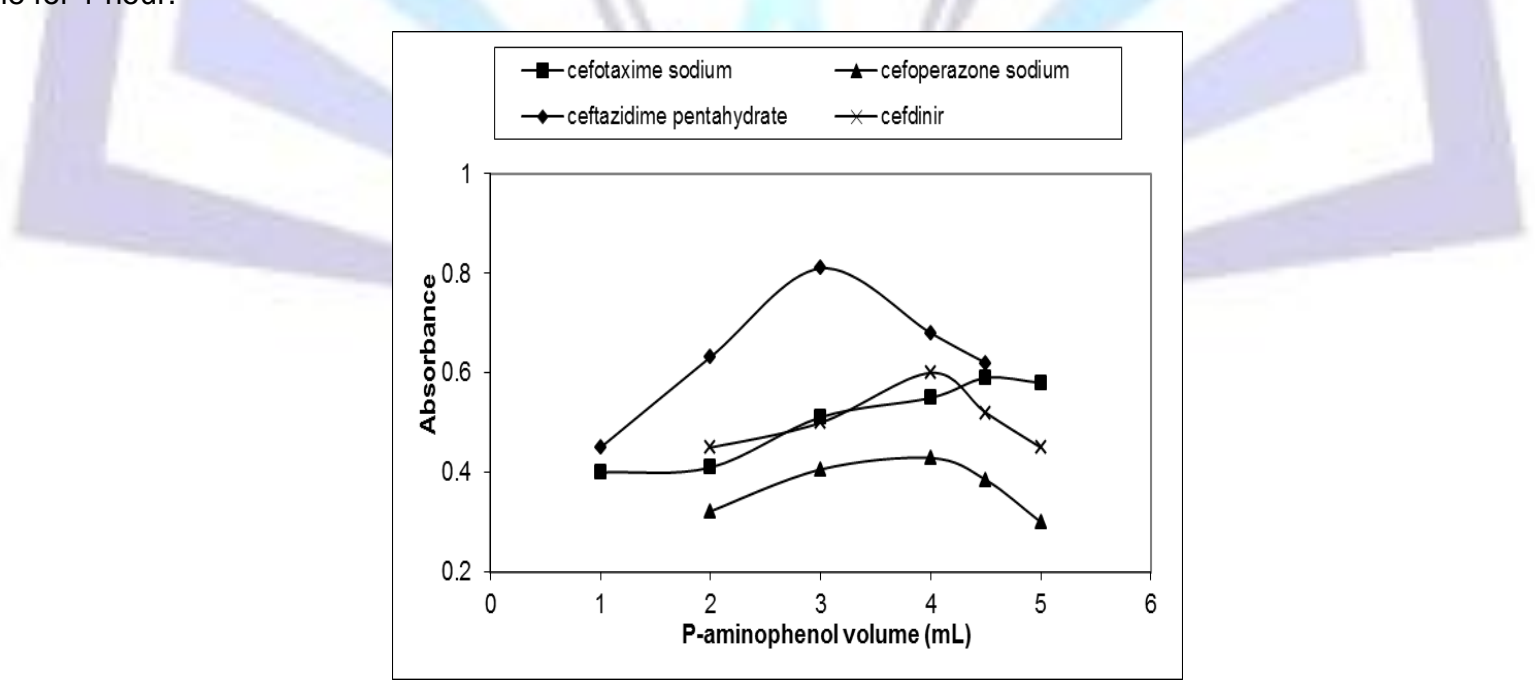

Figure 5: Effect of p-aminophenol volume on thionine dye formation using:
- $48 \mu \mathrm{g} / \mathrm{mL}$ cefotaxime sodium
- $108 \mu \mathrm{g} / \mathrm{mL}$ cefoperazone sodium
- $102 \mu \mathrm{g} / \mathrm{mL}$ ceftazidime pentahydrate
$-24 \mu \mathrm{g} / \mathrm{mL}$ cefdinir 


\subsection{Method developemt (Method B)}

NBS- metol- primary arylamine combination was used for the determination of the oxidant, thereby permitting the indirect assay of many oxidisable substances including drugs in which the drug is oxidized with a known excess of NBS and, after the reaction, the unreacted NBS reacts with metol and primary arylamine and the purple color formed is measured and correlated to drug concentration.

Many pharmaceuticals have been estimated by this approach using NBS as oxidant and sulphanilic acid as primary arylamine .e.g. aspartame [11] and pioglitazone hydrochloride [12].

In this method, the application of NBS-metol-primary amine combination to the determination of (I and III) is described. The method is based on the oxidation of the drug by a known excess of NBS in acidic medium and subsequent determination of the unreacted NBS by interacting with metol and the primary aromatic amine, sulphanilic acid. The studied drugs when added in increasing amounts to a fixed amount of NBS, consume NBS and consequently, there will be a concomitant fall in the NBS concentration. This is observed as a proportional decrease in the absorbance of the reaction mixture on increasing the concentration of drugs. The following scheme illustrates the proposed reaction mechanism.

\section{Drug $\quad+$ Known excess of NBS $\longrightarrow$ 0xidized product of drug + unreacted NBS}<smiles>CN(C)c1ccc(O)c(N(C)C)c1</smiles>

p-N-methylbenzoquinone monoimine (PNMM)<smiles>CNc1ccc(S(=O)(=O)O[Na])cc1C</smiles>

Sulphanilic acid<smiles>CN=C1C=CC(=O)C=C1</smiles><smiles>CN(CCCOC1=CC(=N)C=CC1=N)c1ccc(S(=O)(=O)O)cc1</smiles>

\section{Colored species}

Scheme (3): Proposed reaction mechanism of the studied drugs and NBS-metol-primary amine combination.

\subsubsection{Optimization of the reaction conditions}

The effect of acid type, molarity of hydrochloric acid, NBS volume, metol volume, sulphanilic acid volume, reaction time between drug and NBS, waiting time after addition of sulphanilic acid and time after dilution were studied. It was found that $0.2 \mathrm{M}$ and $0.05 \mathrm{M}$ hydrochloric acid, 0.8 and $2 \mathrm{~mL}$ of NBS solution, 0.5 and $1 \mathrm{~mL}$ of metol solution (Figure 6 ), 0.5 and $1 \mathrm{~mL}$ of sulphanilic acid solution, 15 and 10 minutes reaction time with NBS and 3 minutes waiting time after addition of sulphanilic acid were sufficient to give maximum absorbance. Solutions of ceftazidime can be measured immediately after dilution with water giving stable absorbances. For cefotaxime sodium, the solution should be stand for 5 minutes after dilution then measured due to increasing the absorbances in the first five minutes after dilution. All absorbances for both drugs are stable for 30 minutes. 


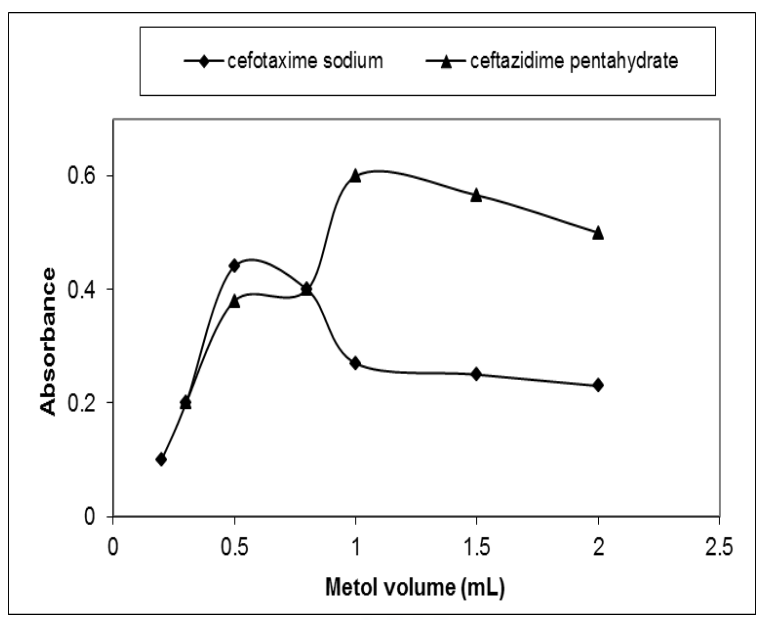

Figure 6: Effect of metol volume on the reaction of NBS-metol-primary amine combination with

\section{- $17 \mu \mathrm{g} / \mathrm{mL}$ cefotaxime sodium $\quad-27 \mu \mathrm{g} / \mathrm{mL}$ ceftazidime pentahydrate}

\subsection{Method development (Method C)}

The use of palladium (II) chloride as a complexing agent for drugs quantitation is very wide. Palladium(II) chloride was found to form complexes of square or 5 -co-ordinate shape [13]. The chelate complex of palladium (II) ions is watersoluble and does not need extraction procedure. Several drugs were determined spectrophotometrically by measuring the color intensity of their complexes with palladium (II) ions, e.g. metoclopramide, promazine [14] and cefotaxime , cefuroxime and cefazolin [6].

Reaction of $\mathrm{Pd}(\mathrm{II})$ chloride with drug (IV) produced yellow complex which was soluble in walpole acetate buffer pH 3.5 . The absorption spectra showed a maximum absorbance at $314 \mathrm{~nm}$.

\subsubsection{Optimization of the reaction conditions}

Effect $\mathrm{pH}$, effect of $\mathrm{KCl}$, effect of reagent volume, effect of reaction time, effect of temperature and effect of order of addition were studied. It was found that $2 \mathrm{~mL}$ of Walpole acetate buffer $\mathrm{pH} 3.5,0.5 \mathrm{~mL}$ of $2 \mathrm{M} \mathrm{KCl}, 1 \mathrm{~mL} 2 \times 10^{-3} \mathrm{M}$ $\mathrm{Pd}(\mathrm{II})$ chloride (Figure 7), 10 minutes were sufficient to give maximum absorbance with cefdinir. Temperatures higher than room temperature caused absorbance decrease. The most suitable order of addition was found to be drug, buffer, $\mathrm{KCl}$ and $\mathrm{Pd}(\mathrm{II})$ chloride. The color produced was stable for 30 minutes.

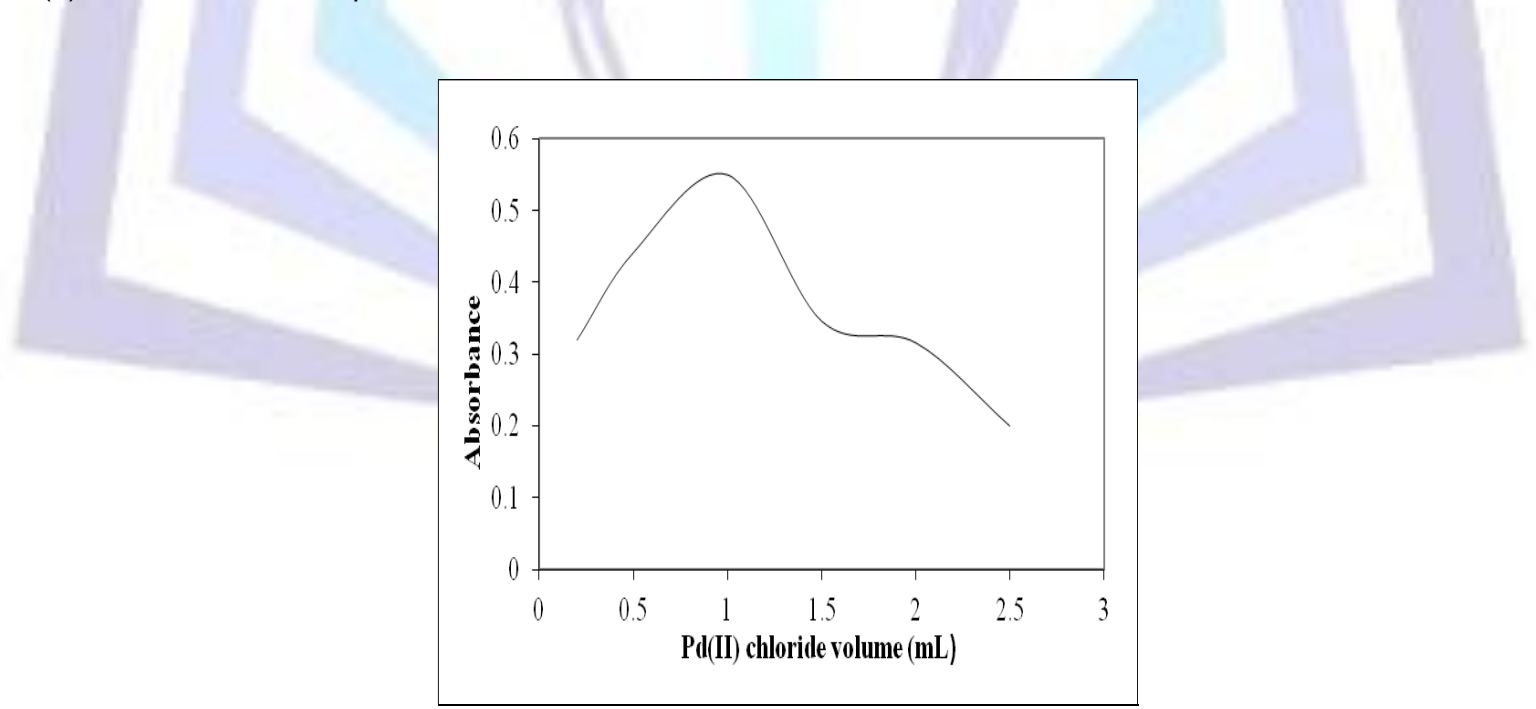

Figure 7: Effect of $\mathrm{Pd}(\mathrm{II})$ chloride volume on the absorbance of the complex formed with $24 \mu \mathrm{g} / \mathrm{mL}$ cefdinir .

\subsubsection{Composition of the complex}

The stoichiometry of the complex between cefdinir and $\mathrm{Pd}(\mathrm{II})$ chloride was studied by applying Job's method of continuous variation [15] using an equimolar $\left(5 \times 10^{-4} \mathrm{M}\right)$ solutions of cefdinir and $\mathrm{Pd}(\mathrm{II})$ chloride. The total volume of drug and $\mathrm{Pd}(\mathrm{II})$ chloride was kept at $2 \mathrm{~mL}$ then the procedure was completed as under the above mentioned procedure. The results obtained showed that the stoichiometric ratio of the complex was (1:1) (reagent:drug) (Figure 8). 


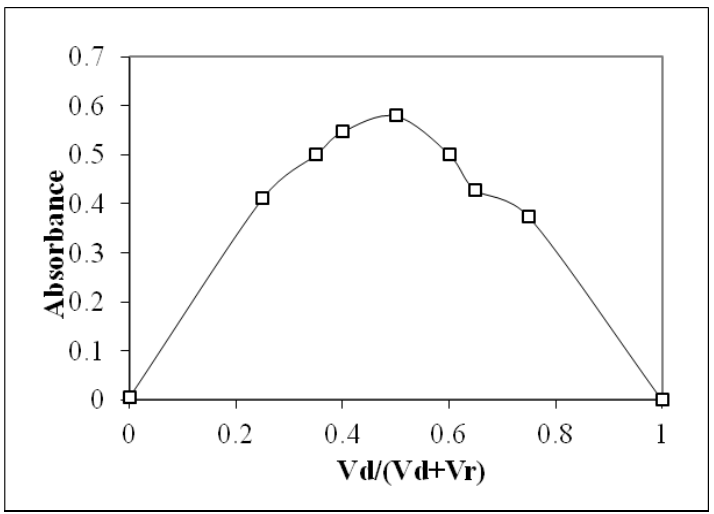

Figure 8: Continuous variation plot for cefdinir $\left(5 \times 10^{-4} \mathrm{M}\right)$ with $\mathrm{pd}(\mathrm{II})$ chloride $\left(5 \times 10^{-4} \mathrm{M}\right)$.

$\mathrm{Vd}$ is the volume taken from drug molar solution. $\mathrm{Vr}$ is the volume taken from Pd (II) chloride molar solution.

\subsubsection{Formation Constant of the Reaction Product}

The formation constant $\left(\mathrm{K}_{\mathrm{f}}\right)$ of the complex was calculated using the following formula [16]:

$$
K_{f}=\frac{\left(A / A_{m}\right)}{\left((1-A) / A_{m}\right)^{n+1} C^{n} n^{n}}
$$

Where; $\mathrm{K}_{\mathrm{f}}$ the formation constant of the complex between cefdinir and $\mathrm{Pd}(\mathrm{II})$ chloride .

$A=$ Maximum absorbance value of the continuous variation curve (Figure 8 ).

$\mathrm{Am}=$ Absorbance value corresponding to the intersection of the two tangents of the continuous variation curve (Figure 8).

$\mathrm{n}=$ Number of $\mathrm{Pd}(\mathrm{II})$ chloride molecules in the complex.

$\mathrm{C}=$ Molar concentration of cefdinir corresponding to maximum absorbance.

The formation constant $\left(\mathrm{K}_{\mathrm{f}}\right)$ of complex was found to be $3.5 \times 10^{4} \mathrm{~L}_{\mathrm{mol}}{ }^{-1}$ indicating high stablility of the complex. The Gibbs free energy change of the reaction $(\Delta G)$ was also calculated using the following equation:

$$
\Delta \mathbf{G}=-2.303 R T \log K_{f}
$$

Where; $\Delta \mathrm{G}=$ Gibbs free energy change of the reaction (K.J./mole).

$\mathrm{R}=$ Universal gas constant (8.314 joules).

$\mathrm{T}=$ Absolute temperature $\left(273+25^{\circ} \mathrm{C}\right)$.

The Gibbs free energy change of the reaction $(\Delta \mathrm{G})$ was found to be $-2.6 \times 10^{4} \mathrm{~K} . \mathrm{J} . / \mathrm{mole}$. It has a negative value which indicates the spontaneous nature of the reaction [16].

\subsection{Method developemt (Method D)}

Ninhydrin (triketohydrindane hydrate) is a carbonyl reagent which can form a purple condensation product which can be measured spectrophotometrically.So, it was applied in the pharmaceutical assay of different nitrogenous compounds such as some penicillins [17] and tranexamic acid [8]. A modified approach for ninhydrin green use was developed for lisinopril determination based on the formation of a yellow colour product with aqueous ninhydrin in the presence of bicarbonate with an absorption maximum at $420 \mathrm{~nm}$ [18]. So the aim of this work is to develop simple green method for cefdinir determination by the reaction with aqueous ninhydrin in bicarbonate medium giving yellow color measured at $433 \mathrm{~nm}$. The green use of ninhyrin leads to short heating time (15 minutes) and avoidance of organic solvent use, so reduces cost.

\subsubsection{Optimization of the reaction conditions}

The effect of $\mathrm{pH}$, volume of $\mathrm{NaHCO}_{3}$, concentration of ninhydrin and heating time were studied. Different molarities of $\mathrm{NaOH}$ were used to study the effect of $\mathrm{pH}$ on the reaction. No color product was formed in $\mathrm{NaOH}$ medium, so the reaction is specific in bicarbonate medium $.1 \mathrm{~mL}$ of $\mathrm{NaHCO}_{3}, 1 \mathrm{~mL}$ of ninhydrin (Figure 9) and heating for 15 minutes were sufficient to give maximum absorbance and stable yellow color product. The developed yellow color was stable for 1 hour. 


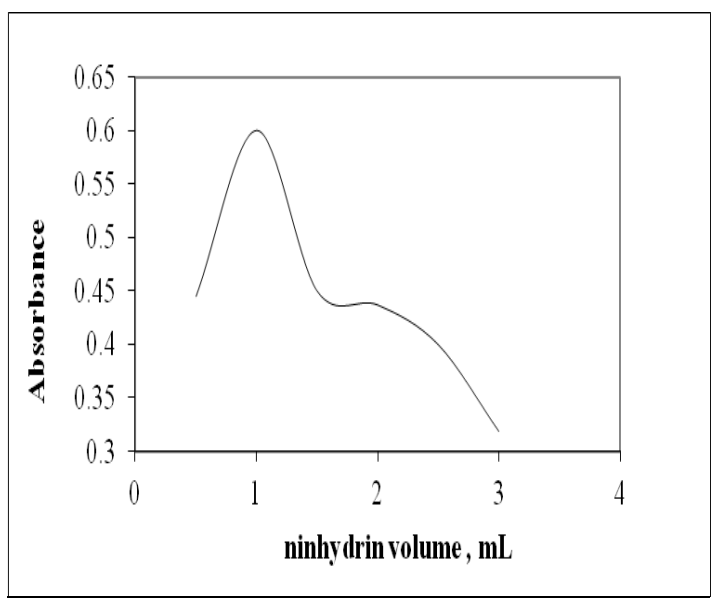

Figure 9: Effect of ninhydrin volume on the absorbance of the reaction product of $17 \mu \mathrm{g} / \mathrm{mL}$ cefdinir.

\subsection{Method E ( conductometric method)}

Conductometric titration is one of the simplest analytical techniques used in drug standardization laboratories. Precipitimetric conductometric titrations using phosphotungstic acid as a titrant are commonly used for the quantitative determination of different compounds eg. reproterol $\mathrm{HCl}$, pipazethate $\mathrm{HCl}$, salbutamol sulphate [19].

The present method aims to introduce new conductometric method for the determination of the cited drugs which is very simple in application and of low expenses but as the same time having a high degree of accuracy and precision when compared to the reported methods.

The conductance measured before any addition of the titrant (volume of phosphotungstic acid equals zero) is due to the formation of $\mathrm{RNHx}^{+}$and $\mathrm{OH}^{-}$by hydrolysis. During titration, replacement of the $\mathrm{RNHx}^{+}$ions by mobile $\mathrm{H}^{+}$occurs resulting in ion associate formation and the conductivity increases. The conductivity continues to increase rapidly after the endpoint. Curve break is observed at molar ratio of $3: 2$ (drug-reagent) for all drugs except for ceftazidime pentahydrate which has a curve break at drug-reagent molar ratio of 1:1.

Representative titration curve is shown in (Figure 4) indicating two straight lines intersecting at the end point. After the end point, sudden change in the slope occurs.

\subsubsection{Optimization of the reaction conditions}

The optimum conditions for performing the titration in a quantitative manner were elucidated as described below.

\subsubsection{Titration medium.}

Preliminary experiments in aqueous solutions of both drug and reagent, drug and reagent solutions in ethanol-water $(50 \%, \mathrm{v} / \mathrm{v})$ mixture, methanolic solutions of both drug and reagent, drug and reagent solutions in methanol-water $(50 \% \mathrm{v} / \mathrm{v})$ mixture and drug and reagent solution in acetone-water $(50 \% \mathrm{v} / \mathrm{v})$ mixture. Aqueous medium led to higher conductance and most sharp end point for all drugs.

\subsubsection{Reagent's concentration.}

The optimum concentration of phosphotungstic acid was found to be $10^{-2} \mathrm{M}$ to give a constant and stable conductance for all drugs. Concentrations less than $10^{-2} \mathrm{M}$ give unstable readings.

\subsubsection{Composition of the complex:}

In $50 \mathrm{~mL}$ volumetric flask, 6 millilitres of $10^{-2} \mathrm{M}$ drug solution were transferred, completed to $50 \mathrm{~mL}$ with bidistilled water , transferred to a beaker and titrated by $10^{-2} \mathrm{M}$ PTA. The conductance was measured after 2 minutes stirring from each addition of reagent solution. A graph of corrected conductivity versus PTA volume was constructed indicating curve break at a molar ratio of $3: 2$ (drug-reagent) except for ceftazidime pentahydrate which has a curve break at drug-reagent molar ratio of $1: 1$.

\subsection{Method validation}

\subsubsection{For the methods (A, B, C and D)}

Standard calibration curves for the cited drugs were constructed by plotting absorbances against concentrations. Beer's law limits, linear regression equations, molar absorptivity and sandell sensitivity were estimated for each method (Table 1). The correlation coefficients were found to be 0.9999 indicating excellent linearity over beer's law limits for all methods (Table 1). The detection limit (LOD) and limits of quantitation for the proposed methods were estimated according to ICH 
[20] and listed in (Table 1). Their values indicate the high sensitivity of the proposed methods. Accuracy and precision were determined by analyzing one concentration of each drug in seven replicates. The relative standard deviation (RSD\%) and percentage relative error (Er\%) were estimated at $95 \%$ confidence levels (Table 2). The results showed that the proposed methods have good reproducibility.

Table 1: Spectral characteristics and statistical data of the regression equations for product formed through reactions of cefdinir in methods $A, C$ and $D$ *.

\begin{tabular}{|c|c|c|c|}
\hline Parameter & Method (A) & Method(C) & Method (D) \\
\hline$\lambda \max (\mathrm{nm})$ & $545 \mathrm{~nm}$ & $314 \mathrm{~nm}$ & $433 \mathrm{~nm}$ \\
\hline Beers law limits $(\mu \mathrm{g} / \mathrm{mL})$ & $3-36$ & $3-26$ & $4-30$ \\
\hline \multicolumn{4}{|l|}{ Regression equation $^{\star \star}$} \\
\hline Slope (b) & 0.024 & 0.0316 & 0.033 \\
\hline Intercept (a) & 0.0337 & 0.0795 & -0.0233 \\
\hline Correlation coefficient $\left(r^{2}\right)$ & 0.9999 & 0.9999 & 0.9999 \\
\hline LOD $\mu \mathrm{g} / \mathrm{mL}$ & 2.16 & 2.36 & 6.34 \\
\hline LOQ $\mu \mathrm{g} / \mathrm{mL}$ & 6.55 & 7.15 & 19.23 \\
\hline Sandell sensitivity $\mu \mathrm{g} . \mathrm{cm}^{-2}$ & 0.04 & 0.02 & 0.33 \\
\hline$\varepsilon\left(\times 10^{4}\right)$ L.mol $^{-1} . \mathrm{cm}^{-1}$ & 1.09 & 1.65 & 0.12 \\
\hline
\end{tabular}

${ }^{*}$ Average of 3 experiments

${ }^{\star *} A=a+b c$

Table 2: The intra-day and inter-day accuracy and precision data for cefoperazone sodium using the proposed methods (A and B).

\begin{tabular}{|c|c|c|c|c|c|c|c|c|c|c|}
\hline & & & atra-day & & & & & nter-day & & \\
\hline & $\begin{array}{l}\text { Taken } \\
\mu \mathrm{g} / \mathrm{mL} \text { ) }\end{array}$ & $\begin{array}{l}\text { Found } \\
(\mu \mathrm{g} / \mathrm{mL})^{\mathrm{a}}\end{array}$ & $\begin{array}{c}\text { Recovery } \\
\%\end{array}$ & $\begin{array}{l}\text { Precision } \\
\text { RSD }^{\text {b }}\end{array}$ & $\begin{array}{c}\text { Accuracy } \\
\text { Er\% }^{c}\end{array}$ & $\begin{array}{l}\text { Taken } \\
(\mu \mathrm{g} / \mathrm{mL})\end{array}$ & $\begin{array}{l}\text { Found } \\
(\mu \mathrm{g} / \mathrm{mL})^{\mathrm{a}}\end{array}$ & $\begin{array}{c}\text { Recovery } \\
\%\end{array}$ & $\begin{array}{l}\text { Precision } \\
\text { RSD }^{\text {b }}\end{array}$ & $\begin{array}{c}\text { Accuracy } \\
\text { Er\% }{ }^{c}\end{array}$ \\
\hline ethod(A) & 90 & 89.81 & 99.79 & 0.83 & -0.21 & 90 & 89.96 & 99.96 & 0.89 & -0.04 \\
\hline ethod(B) & 26 & 25.79 & 99.19 & 0.64 & -0.81 & 26 & 25.74 & 99 & 0.53 & -1 \\
\hline
\end{tabular}

a Average of seven determinations.

b RSD\%, percentage relative standard deviation

c Er \%, percentage relative error.

\subsubsection{For Method E:}

Recovery study of the cited drugs content in their commercial preparations was performed using the proposed method. (Table 3) showed that the proposed method is accurate and reproducible over a concentration range of $3-30 \mathrm{mg}$. Table 4 showed comparison of the results obtained using method D with the reported method [21] using Student t-test and Variance ratio F-test at $95 \%$ confidence level . 
Table 3: Application of method (E) to the determination of cefdinir in its dosage forms*

\begin{tabular}{|c|c|c|c|c|c|}
\hline \multicolumn{3}{|c|}{ Dinar $\AA$ suspension } & \multicolumn{3}{|c|}{ Dinar® capsules } \\
\hline Taken $(\mathrm{mg})$ & Found (mg) & Recovery\% & Taken (mg) & Found (mg) & Recovery\% \\
\hline 3 & 3.05 & 101.58 & 2 & 2 & 100 \\
\hline 4 & 4 & 100 & 4 & 4.05 & 101.19 \\
\hline 6 & 6.07 & 101.19 & 7 & 7.05 & 100.68 \\
\hline 8 & 8.1 & 101.19 & 8 & 8.05 & 100.60 \\
\hline 10 & 10 & 100 & 12 & 11.90 & 99.20 \\
\hline 12 & 11.91 & 99.21 & 14 & 13.95 & 99.66 \\
\hline 14 & 14.05 & 100.34 & & & \\
\hline mean & & 100.50 & & & 100.22 \\
\hline S.D. & & 0.85 & & & 0.73 \\
\hline S.E. & & 0.32 & & & 0.30 \\
\hline R.S.D. & & 0.84 & & & 0.73 \\
\hline Variance & & 0.72 & & & 0.54 \\
\hline
\end{tabular}

${ }^{*}$ Average of 3 determinations

Table (4): Statistical data for determination of ceftazidime pentahydrate through the proposed methods compared with the reported method [21].

\begin{tabular}{|c|c|c|c|c|}
\hline & Method(A) & Method(B) & Method(E) & $\begin{array}{c}\text { Reported } \\
\text { method [21] }\end{array}$ \\
\hline Mean \pm S.D & $99.73 \pm 0.46$ & $100.09 \pm 0.40$ & $100.05 \pm 0.62$ & $99.97 \pm 0.288$ \\
\hline N & 9 & 9 & 6 & 8 \\
\hline Variance & 0.21 & 0.16 & 0.37 & 0.08 \\
\hline Student-t-test & $1.27(2.131)^{*}$ & $0.71(2.131)^{*}$ & $0.33(2.17)^{*}$ & - \\
\hline F-test & $2.63(3.60)^{*}$ & $2(3.60)^{*}$ & $4.625(4.88)^{*}$ & - \\
\hline
\end{tabular}

*Theoretical values of $t$ and $F$ at $p=0.05$

\subsection{Analytical applications}

The proposed methods were successfully applied to determine the cited drugs in their commercial dosage forms. Recovery studies were performed (Tables 3 and 5). The results validation was determined by comparison with the reported method [21] using Student t-test and Variance ratio F-test at 95\% confidence level (Table 4).It was found that no significant differences between the proposed methods and reported method [21]. 
Table 5: Application of standard addition technique for determination of cefotaxime sodium in its pharmaceutical dosage forms in methods $A$ and $B^{*}$.

\begin{tabular}{|c|c|c|c|c|c|c|c|}
\hline \multicolumn{4}{|c|}{ Method (A) } & \multicolumn{4}{|c|}{ Method (B) } \\
\hline $\begin{array}{c}\text { Claimed } \\
\text { taken } \\
\mu \mathrm{g} / \mathrm{mL}\end{array}$ & $\begin{array}{l}\text { Authentic } \\
\text { added } \\
\mu \mathrm{g} / \mathrm{mL}\end{array}$ & $\begin{array}{l}\text { Found } \\
\text { conc. } \\
\mu \mathrm{g} / \mathrm{mL}\end{array}$ & $\begin{array}{c}\text { Recovery } \\
\%\end{array}$ & $\begin{array}{c}\text { Claimed } \\
\text { taken } \\
\mu \mathrm{g} / \mathrm{mL}\end{array}$ & $\begin{array}{c}\text { Authentic } \\
\text { added } \\
\mu \mathrm{g} / \mathrm{mL}\end{array}$ & $\begin{array}{l}\text { Found } \\
\text { conc. } \\
\mu \mathrm{g} / \mathrm{mL}\end{array}$ & $\begin{array}{c}\text { Recovery } \\
\%\end{array}$ \\
\hline 6 & --- & 6.10 & 101.71 & 2 & --- & 2.04 & 102.07 \\
\hline & 6 & 6.10 & 101.71 & & 2 & 2 & 100 \\
\hline & 12 & 12.09 & 100.72 & & 4 & 4.07 & 101.65 \\
\hline & 18 & 18.15 & 100.83 & & 8 & 7.99 & 99.90 \\
\hline & 24 & 23.98 & 99.90 & & 10 & 9.93 & 99.34 \\
\hline & 30 & 30.28 & 100.92 & & 12 & 12.12 & 101.03 \\
\hline & 36 & 36.02 & 100.07 & & 14 & 14.19 & 101.36 \\
\hline & 42 & 41.93 & 99.83 & & 16 & 16.26 & 101.60 \\
\hline & 48 & 48.15 & 100.31 & & 18 & 18.32 & 101.79 \\
\hline & 54 & 54.21 & 100.39 & & 22 & 22.04 & 100.19 \\
\hline & 60 & 59.49 & 99.15 & & 24 & 24.40 & 101.65 \\
\hline Mean & & & 100.50 & & & & 100.96 \\
\hline Variance & & & 0.61 & & & & 0.87 \\
\hline SD & & & 0.78 & & & & 0.93 \\
\hline SE & & & 0.25 & & & & 0.30 \\
\hline
\end{tabular}

${ }^{\star}$ Average of three experiments

\subsection{Human urine (for method C)}

Method C was successfully applied to determine cefdinir in spiked human urine samples with excellent precision and accuracy (Table 6) .No interference was found from the biological urine matrix. Moreover, the linearity of the proposed method was checked over a concentration range of $4-26 \mu \mathrm{g} \cdot \mathrm{mL}^{-1}$. Excellent linearity was observed. The regression equation was found to be $y=0.0347 x+0.0726$. The correlation coefficient $\left(r^{2}\right)$ was found to be 0.9993 . The detection (LOD) and quantitation limits (LOQ) were found to be 1.64 and $4.97 \mu \mathrm{g} . \mathrm{mL}^{-1}$ respectively. Their values confirm the sensitivity of the proposed method in human urine.

So, The proposed methods are simple, green, accurate and precise in determining the cited drugs in its pharmaceutical formulations and human urine without interference from common excipients or biological matrix. The proposed methods have higher sensitivity than many of the reported methods. All methods are green analytical methods so, they are inexpensive and ecofriendly. Moreover, they are less time-consuming and do not require difficult extraction procedures. So, the proposed methods are suitable for routine analysis of the cited drugs in control laboratories. 
Table 6: Application of method (C) for cefdinir determination in spiked human urine.

\begin{tabular}{|c|c|c|}
\hline Added ( $\mu \mathrm{g} / \mathrm{mL}$ ) & Found $(\mu \mathrm{g} / \mathrm{mL})$ & Recovery\%* \\
\hline 4 & 4.07 & 101.66 \\
\hline 6 & 6.03 & 100.47 \\
\hline 10 & 10.05 & 100.47 \\
\hline 14 & 14.22 & 101.60 \\
\hline 16 & 16.34 & 102.16 \\
\hline 18 & 18.21 & 101.18 \\
\hline 20 & 20.55 & 102.77 \\
\hline 24 & 24.70 & 102.91 \\
\hline 26 & 26.60 & 102.30 \\
\hline Mean \pm & & 90 \\
\hline
\end{tabular}

${ }^{*}$ Average of 3 experiments

\section{ACKNOWLEDGMENTS}

Finally, Authors express their great thanks to Dr. Omnia Ahmed Emam Ismaiel in the Analytical Chemistry Department, Zagazig University for their great advices through this work. Also, authors would like to ensure that they do not have any conflict of interest with any companies.

\section{REFERENCES}

[1] Williams, J.D., Naber, K.G., Bryskier,A., Hoiby,N., Gould, I.M., Periti, P., Giamarellou,H. and Rouveix, B. 2001 Classification of oral cephalosporins. A matter for debate. Int. J. Antimicrob. Agents , 17 ( June 2001), 443-450 .

[2] British Pharmacopoeia.2007 London, Her Majesty's Stationery Office.

[3] Japanese Pharmacopeia,2001 Official Monograph XIV.

[4] Arasimhamurthy, L.N, Basayya, P.S and Pai, S.P.N. 2009 A Stability-Indicating HPLC Method for Cefoperazone. Eurasian Journal of Analytical Chemistry.4(2009), 110-118.

[5] Rageh, A.H., El-Shaboury, S.R., Saleh, G.A. and Mohamed, F.A. 2010 Spectophotometric method for determination of certain cephalosporins using 4-chloro-7-nitrobenzo-2-oxa-1, 3-diazole (NBD-Cl).Natural Science. 2 (2010), 828840.

[6] Bagher, A.G., Yosefi, A., Rezvani, M.and Roshanzamir, S. 2012 Spectrophotometric complexation of cephalosporins with palladium (II) chloride in aqueous and non-aqueous solvents. Spectrochimica Acta Part A. 89 ( January 2012), $317-321$.

[7] Lingane, J. J. 1958 Electroanalytical Chemistry, 2nd Ed., Interscience, NewYork.

[8] Ansari, T.M., Raza, A. and Rehman, A.U. 2005 Spectrophotometric determination of tranexamic acid in pharmaceutical bulk and dosage forms. Anal. Sci.21(September 2005), 1133-1135.

[9] Darwish, A., Hussein, A., Mahmoud, M. and Hassan, A. A. 2008 sensitive spectrophotometric method for the determination of $\mathrm{H}_{2}$-receptor antagonists by means of $\mathrm{N}$-bromosuccinimide and p-aminophenol. Acta Pharm, 58 (2008), 87-97.

[10] Espinosa Boscha, M., Ruiz Sánchezb, A.J., Sánchez Rojasc, F. and Bosch Ojedac, C. 2008 Recent developments in the analytical determination of cefadroxil. Asian Journal of Pharmaceutical Sciences, 3(2008), 217-232.

[11] Prasad, U.V., Divakar, T.E. and Sastry, C.S.P. 1988 New methods for the determination of aspartame. Food Chemistry, 28(1988), 269-278.

[12] Abdelmonem, A.A., Ragab, G.H., Hashem H.A. and Bahgat, E.A. 2012 High performance liguid chromatographic and Spectrophotometric determinations of pioglitazone - $\mathrm{HCl}$ either alone or in combination with metformin- $\mathrm{HCl}$. Journal of Liquid Chromatography \& Related Technologies, 35(2012), 2706-2723.

[13] Gorog, S. 1995 Ultraviolet-visible spectrophotometry in pharmaceutical analysis,CRC Press.

[14] Abdel-Gawad, F. M. and El-Guindi, N. M. 1995 Spectrophotometric investigation of metoclopramide and promazine palladium II complexes. Egyptian Journal Of Pharmaceutical Sciences, 36(1995), 361-371. 
[15] Rose, J., 1964 Advanced Physico-Chemical Experiments, Pittman, London.

[16] Inczedy, J.1976 Analytical Application of Complex Equilibriia . Jhon Wiley \& Sons Inc. Budapest.

[17] Hiremath, R.C. and Mayanna, S. M. 1986 Spectrophotometric method for assay of pencillins. Mikrochim. Acta. 88(1986) , 265-270.

[18] Kanakapura, B., Kalsang, T., Salmara, G.H. and Kanakapura, B.V. 2009 Spectrophotometric Determination of Lisinopril in Pharmaceuticals Using Ninhydrin- a Modified Approach. Journal of Food and Drug Analysis.17(2009), 9399.

[19] Issa, Y. M. , Shoukry, A. F. and El-Nashar, R. M. 2001 Conductimetric determination of reproterol HCl and pipazethate $\mathrm{HCl}$ and salbutamol sulphate in their pharmaceutical formulations. 2001 Journal of Pharmaceutical and Biomedical Analysis, 26(2001), 379-386.

[20] 2005 International Conference On Harmonisation, ICH, Of Technical Requirments For Registeration Of Pharmaceuticals For Human Use.

[21] Marwa, S.E, Abdalla, S., ELBokiny, M.N. and Hawa, M.K. 2003 Spectrophotometric Determination of cefpime Hydrochloride, Cefoperazone sodium , Ceftazidime pentahydrate, Cefuroxime sodium and Examsylate using Ammonium Molybdate. Scientia Pharmaceutica. 71(2003), 211-228 . 